\title{
A new method to seek the process of tsunami generation -newly discovered waves at the 2003 Tokachi-oki earthquake-
}

\author{
${ }^{*}$ Hitoshi Mikada ${ }^{(1)}$, and Hiroyuki Matsumoto ${ }^{(2)}$ \\ (1) Graduate School of Engineering, Kyoto University \\ (2) Japan Agency for Marine-Earth Science and Technology (JAMSTEC)
}

\begin{abstract}
At the 2003 Tokachi-oki earthquake of M8, seafloor phenomena such as a generation process of tsunami, seafloor uplifts, etc., were observed using a cabled observatory installed on the seafloor. The seafloor uplifts were observed not before the main shock but continuously after the main shock. The uplifts were $0.35,0.37$, and $0.12 \mathrm{~m}$ for epicentral distances of $25.5,31.4$, and $81.8 \mathrm{~km}$, respectively. Pressure fluctuations that took place co-seismically show about 100 times in amplitude to those observed as the uplifts. The uplift of the seafloor generated not only tsunami but high amplitude acoustic waves. Both the tsunami and acoustic waves were generated by the uplift and superposed to each other. After the main shock, a continuous uplift of the seafloor is observed at the all three pressure gauge locations and the rate of uplift was about 0.004 $\mathrm{m} /$ day. These phenomena may imply that there was a change in the state of friction on the plate boundary interface by the main shock. In this paper, we demonstrate what was observed using ocean bottom pressure gauges installed right above the focal area of the earthquake, and then discuss these phenomena in tsunami generation and in post-seismic slip processes.
\end{abstract}

KEYWORDS: plate boundary earthquake, tsunami, acoustic wave, crustal deformation

\section{Introduction}

The 2003 Tokachi-oki earthquake took place on September 25 2003, at 19:50 (UTC) at almost the same location as the 1952 Tokachi-oki earthquake (Watanabe et al, 2004 [1]). The focal area of the Tokachi-oki earthquakes is close to the southern end of the Kuril trench where an arc-arc junction from the Kuril to Japan trench began as a result of the southwestward migration of the Kuril forearc sliver (Kusunoki and Kimura, 1998 [2]). The focal area is in a seismogenic zone of the North American and Pacific plates where the latter subducts beneath the former in an oblique direction with a rate of $8.5 \mathrm{~cm} /$ year (DeMets, 1994 [3]). The amount of dislocation of the 2003 Tokachi-oki earthquake was estimated from 3 to $5 \mathrm{~m}$ on the slip interface from an inversion analysis of teleseismic signals (Yamanaka and Kikuchi, 2004 [4]).

In the focal area of the earthquake, a cabled observatory was deployed in 1999 and recorded, on the seafloor, both seismic and tsunamic fluctuations caused by this megathrust earthquake. The data provided us indispensable information on what took place at the earthquake. Pressure gauge data brought new insight on tsunami generation process and crustal deformation. Also, the observatory is continously recording post-seismic crustal uplift even almost a year after the main shock (Miyazaki et al., 2004 [5]). This phenomena need to be also described for future monitoring of earthquakes taking place in seismogenic zones. Cabled observatories at a seismogenic zone could be used to reveal new phenomena what has not been observed, and it is necessary to summarize what were observed using our cabled observatory at the 2003 Tokachi-oki earthquake.

In this paper, we try to describe what were observed on the seafloor at the time of the M8 megathrust earthquake. The observations of the seafloor uplift associated with the earthquake are described based on acquired data on the seafloor. Unfortunately, there is no remarkable short-term precursory resolved until now in available data from the cabled observatory. As discussed in Watanabe et al. (2004) [1], the cabled observatory has proven the effectiveness of such observation system in the monitoring of earthquakes at the southwestern end of the Kuril seismogenic zone. Discussions finally make it clear that it is necessary to enhance the resolution or signal-to-noise ratio of observations on top of the existing technology of cabled observatories. Especially, much closer access should be tried to seismogenic zones to monitor deep processes or to detect any precursory of plate boundary megathrust earthquakes.

\section{The 2003 Tokachi-oki earthquake}

As briefly investigated by Takahashi et al. (1999) [6], crustal deformation is in progress around the Hokkaido island caused by the plate motion of the three major plates, i.e., the Pacific, North American and Eurasian plates. The subduction zone, off Tokachi located at the boundary between the Pacific and Eurasian plates, has become a seismically inactive region compared to the other part of the Kuril trench seismogenic zone in the last decade (Takahashi and Kasahara, 2003 [7]). At the same time, two disaster intraplate events, the 1993 Kushiro-oki earthquake (Takeo, et al., 1993 [8]), and the 1994 Hokkaido Toho-oki earthquakes (Takahashi and Hirata, 2003 [9]), started to take place in the southern side of the Kuril subduction zone. A cabled observatory was deployed in the southwestern end of the Kuril subduction zone in 1999 and consists

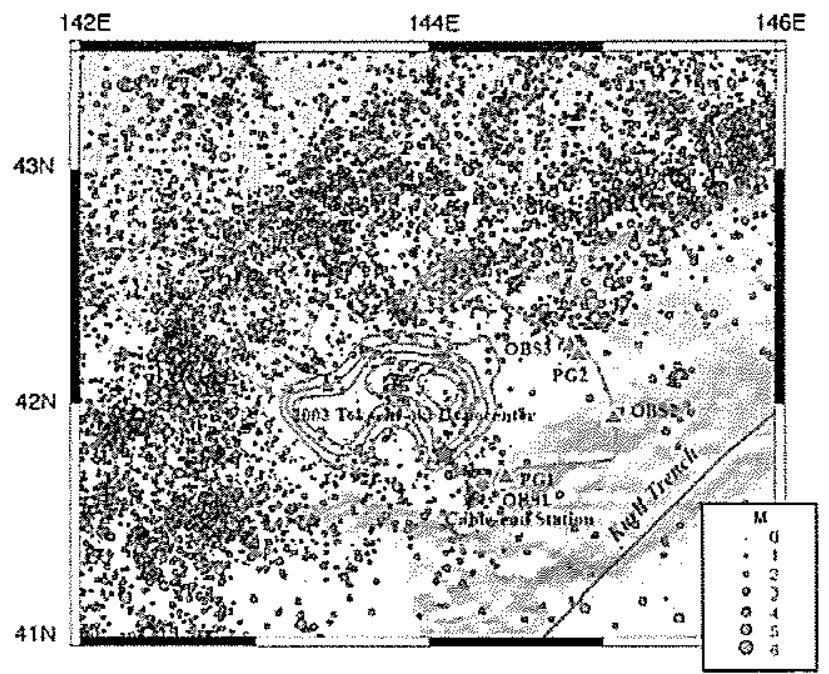

Figure 1 The locations of cabled observatory. Dots are for epicentral distribution of microearthquakes during a period from March 2000 to August 2003. Green contours are drawn every one meter of fault slip at the plate boundary (Yamanaka and Kikuchi, 2003 [4]). 
Table 1 Location of the earthquake and sensors of the cabled observatory (Tokyo Datum). Depths are all in km below the sea level. Delta, rightmost column of the table, represents epicentral distances from the location of the 2003 Tokachi-oki earthquake. The locations of the sensors, sensor types, etc., are found in Hirata, et al. (2002) [10].

\begin{tabular}{ccccc}
\hline & Latitude & Longitude & Depth bsl $/ \mathrm{km}$ & Delta $/ \mathrm{km}$ \\
\hline 2003 Tokachi-oki Earthquake (JMA) & $41^{\circ} 46.7^{\prime} \mathrm{N}$ & $144^{\circ} 04.7^{\prime} \mathrm{E}$ & 42 & 0 \\
PG1 & $41^{\circ} 42.076^{\prime} \mathrm{N}$ & $144^{\circ} 26.486^{\prime} \mathrm{E}$ & 2.340 & 31.4 \\
PG2 & $42^{\circ} 14.030^{\prime} \mathrm{N}$ & $144^{\circ} 51.149^{\prime} \mathrm{E}$ & 2.227 & 81.7 \\
OBS1 & $41^{\circ} 41.085^{\prime} \mathrm{N}$ & $144^{\circ} 23.945^{\prime} \mathrm{E}$ & 2.481 & 28.6 \\
OBS2 & $41^{\circ} 56.375^{\prime} \mathrm{N}$ & $145^{\circ} 03.712^{\prime} \mathrm{E}$ & 3.337 & 83.6 \\
OBS3 & $42^{\circ} 15.023^{\prime} \mathrm{N}$ & $144^{\circ} 48.870^{\prime} \mathrm{E}$ & 2.138 & 80.2 \\
\hline \hline
\end{tabular}

of three omni-directional tri-component seismometers, two highprecision pressure gauges, and a cable-end benthic environment monitoring sensors (Hirata et al., 2002 [10]; Table 1). The two pressure gauges (PG1 and PG2) are located about about $31.4 \mathrm{~km}$ southeast ( $2283 \mathrm{~m}$ below sea level: denoted as mbsl hereafter) and $81.7 \mathrm{~km}$ northwest $(2248 \mathrm{mbsl})$ from the epicenter, respectively (Fig. 1). The closest seismometer is located about $28.2 \mathrm{~km}$ in the epicentral distance from the hypocenter. The locations of hypocenter (determined by the Japan Meteorlogical Agency, denoted as JMA hereafter) of the 2003 Tokachi-oki earthquake and sensors of the cabled observatory are summarized in Table 1.

\section{Observed Data}

The two high-precision pressure gauges (maximum resolution of $0.3 \mathrm{~mm}$ ) records $0.1 \mathrm{~Hz}$ sampled pressure fluctuations in water depth. They all recorded invaluable abrupt changes in pressure, i.e., the water depths, at the time of the earthquake at these three locations. After a tide compensation using a method proposed by Matsumoto et al. (2000) [11], it has become clear that the pressure gauges have recorded vertical uplift of seafloor. The vertical displacements caused by the main shock at these sensor locations are estimated as 0.37 and $0.12 \mathrm{~m}$, respectively at the PG1 and PG2 locations (Fig. 2). This is the first time to record such a crustal uplift in the offshore at the time of plate-boundary earthquakes in the past. The model for the synthetic tidal pressure fluctuations matches quite well with the observed before the earthquake. At the time of the main shock, the pressure gauges recorded high amplitude pressure fluctuations with a period of 6 seconds as shown in Fig. 3. The amplitudes of these fluctuations are ca. 50 and 5 meters in peak-to peak in equivalent water depth at PG1 and PG2 locations, respectively. Therefore, the ratio of pressure fluctuations against the crustal uplifts might be about 50 independently from the location on the seafloor. Tsunamis are generated by uplift or subsidence of seafloor through transportation of a potential energy of water column, and periods of tsunami waves are order of several tens of minutes. Therefore, the observed high pressure fluctuations cannot be explained by the tsunami.

After the main shock, tidal gauge data show a linear trend in the difference between the synthetic and observed water depth (Fig. 3). The rate of the linear uplifts at the pressure sensor locations are estimated as 4.1 and $3.9 \mathrm{~mm} /$ day respectively at the PG1 and PG2 locations over a period of two months after the main shock. Although the difference between the observed and estimated was almost constant before the main shock, the fluctuation of the difference became unstable after the main shock and the uplift of the seafloor continues.

\section{Cause of pressure fluctuations}

Kajiura (1970) [12] formulated the generation of tsunami using a linear wave equation:
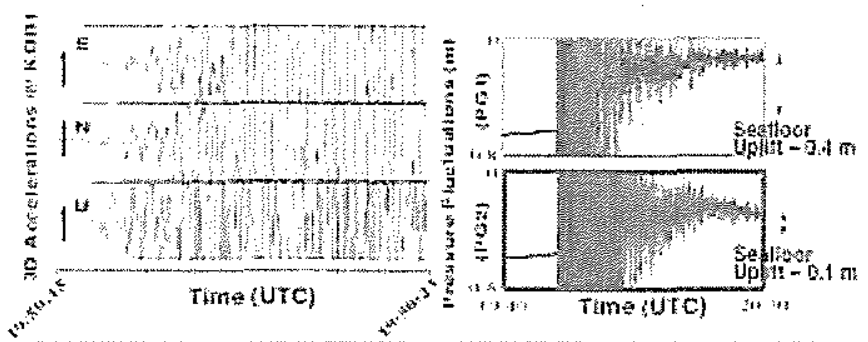

Figure 2 Recorded seismic and pressure gauge data at the time of the 2003 Tokachi-oki earthquake (Watanabe et al., 2004 [1]). Maximum amplitudes of pressure fluctuations are about 40 and $10 \mathrm{~m} \mathrm{P-P} \mathrm{in} \mathrm{equivalent} \mathrm{water} \mathrm{depths} \mathrm{at} \mathrm{PG1} \mathrm{and} \mathrm{PG2}$ locations. Since these values are about 100 times of the crustal uplifts of the seafloor, the pressure values are clipped in the figure.

$$
\nabla^{2} \varsigma-\frac{1}{c^{2}} \frac{\partial^{2} \zeta}{\partial t^{2}}=-\frac{1}{c^{2}} \frac{\partial^{2} w_{B}}{\partial t^{2}}
$$

where $c, \zeta$ and $w_{B}$ denote tsnami propagation velocity, free sea surface elevation, and vertical velocity of seafloor movement, respectively. With the gravitational acceleration $g$ and a water depth $h$, the tsunami propagation velocity is described as:

$$
c^{2}=g h
$$

The utilization of a free space Green's function yields a general solution of Eq. 1 in an integral form as follows:

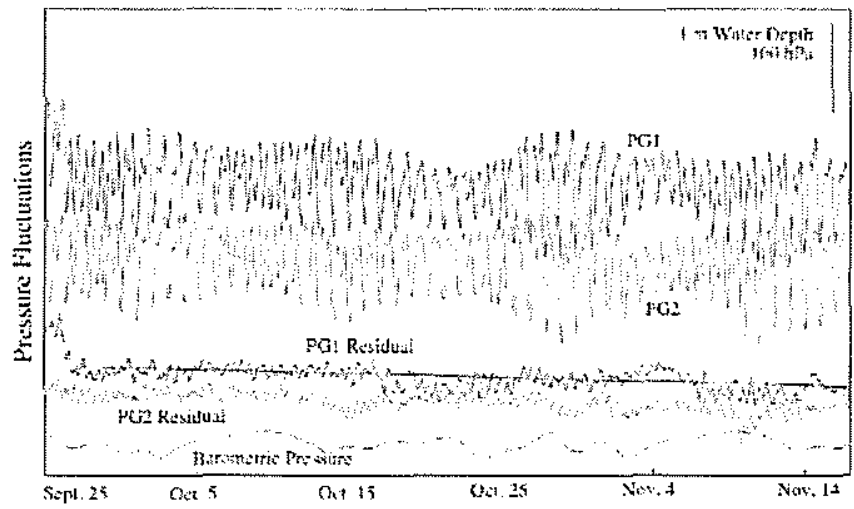

Figure 3 Linear seafloor uplift of ca. $4 \mathrm{~mm} /$ day was observed at $P G 1$ and PG2 locations after the main shock. Note that vertical scale of the figure is in reverse direction to that of Fig. 2. Top two curves are for acquired raw pressure fluctuations. Middle two curves are pressures after the subtraction of the tidal components. The bottom curve is for barometric pressure for demonstrating little correlation of fluctuations. 


$$
\varsigma(\vec{r}, t)=\frac{1}{4 \pi c^{2}} \int_{0}^{t} d t_{0} \iint_{S} G\left(\vec{r}, t \mid \vec{r}_{0}, t_{0}\right) \frac{\partial^{2} w_{B}}{\partial t^{2}} d S\left(\vec{r}_{0}\right)
$$

where $\vec{r}$ denotes the position vector, S the surface of the source area on the seafloor, the suffix 0 for source quantities. It is necessary to take numerical approaches for further discussion of the solutions in general case studies as depicted in the form of the solution (Eq. 3). Using the formulation of Kajiura (1970) [12] for a case of uniform uplift in a rectangular region, we could derive qualitative estimates of dynamic pressure fluctuations for basically two kinds of waves. If we assume a constant velocity $\left(w_{0}\right)$ uplift of the seafloor for a time duration of T, one may write as follows.

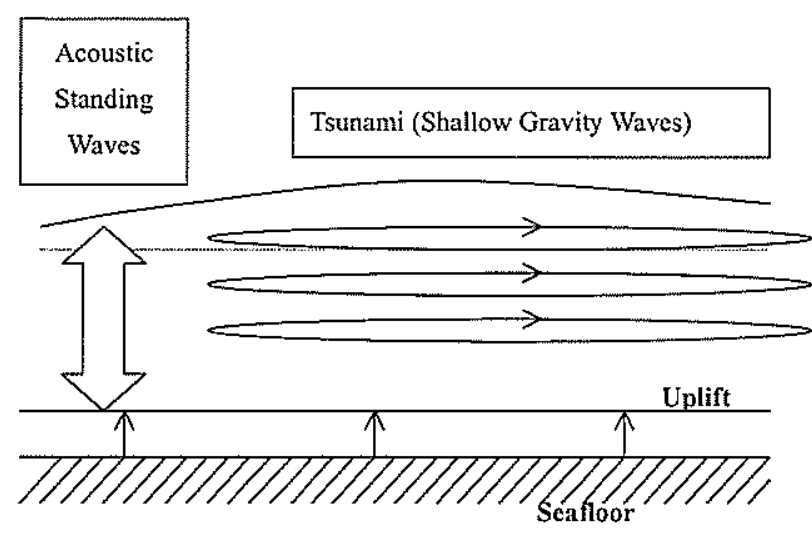

Figure 4 Waves generated when the seafloor uplifts Coseismically. Acoustic and tsunami waves are generated by compressibility and incompressibility of sea water, respectively.

$$
\begin{array}{cc}
w_{B}=0 & t<0, t>T \\
w_{B}=w_{0} & 0 \leq t \leq T
\end{array}
$$

One kind of waves derived from Eq. (3) is tsunami having an approximate amplitude of $w_{0} T$ in pressure in equivalent water depth at the location of pressure measurement on the seafloor. The other kind of waves derived from Eq. (3) is an acoustic wave which is generated by the seafloor uplift. If we assume $T \leq 2 \sqrt{h / g}$, then the acoustic wave has an approximate amplitude of $v w_{0} / g$ where $v$ denotes acoustic wave velocity. The acoustic wave bounces up and down between the seafloor and forms a standing wave. Therefore, a vertical water column has a quarter wavelength of that acoustic wave. and the dominant frequency of the acoustic wave can uniquely be obtained from the water depth at the location of pressure measurement on the seafloor.

\section{Crustal uplift and pressure gauges}

The 2003 Tokachi-oki earthquake has proven that pressure gauges have capability to detect crustal uplift in the offshore. Figures 3 and 5 displays continuous uplift of the seafloor since the main shock. Although already several months have passed since the main shock, the uplift of the seafloor still continues with gradual asymptotic rate change (Fig. 5). The pressure gauges were installed in 1999, and pressure gauges record continous subsidence until the time of the main shock (Fig. 6).

\section{Discussions}

There might be two types of findings in our study on data acquired by the cabled observatory.

The pressure gauge data indicate that seafloor uplift in the eastern sensor (PG2) was about one third of that of the eastern sensor (PGl) at the time of the main shock. The initial slip on the fault plane was larger in the western side of the focal region (Yamanaka and Kikuchi, 2003) [11], and aftershocks started eastward migration six hours after the mainshock. Miyazaki et al. (2004) [5] have reported that the post-seismic slip took place adjacent to but different from the coseismic fault rupture of the main shock analyzing land-based GPS data. Postseismic seafloor uplift for two pressure gauge locations show almost identical rate and uplift values. The present results from offshore cabled observatory would provide supplementary but definite data to further analyses of slip motion at the plate boundary. These results might imply that the seismic fault plane has not only spatial variations but also time-scale variations in frictional properties. Post-seismic slip could be

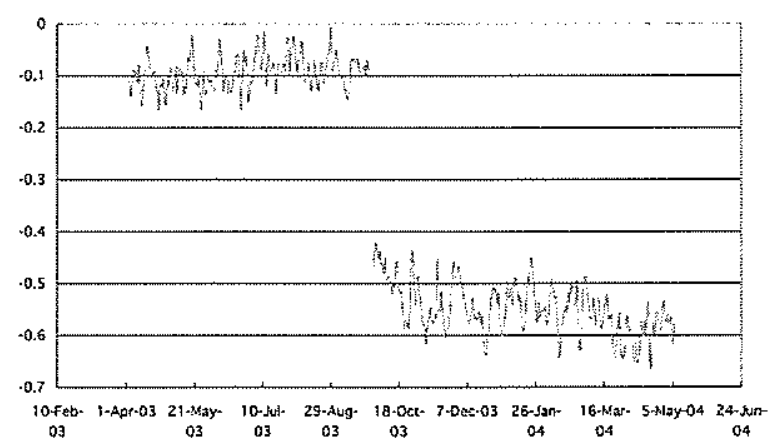

Figure 5 Postseismic crustal uplift at PGl. The rate of postseismic change has been gradually decreasing, but is still on-going. The vertical axis depicts relative subsidence in meters.

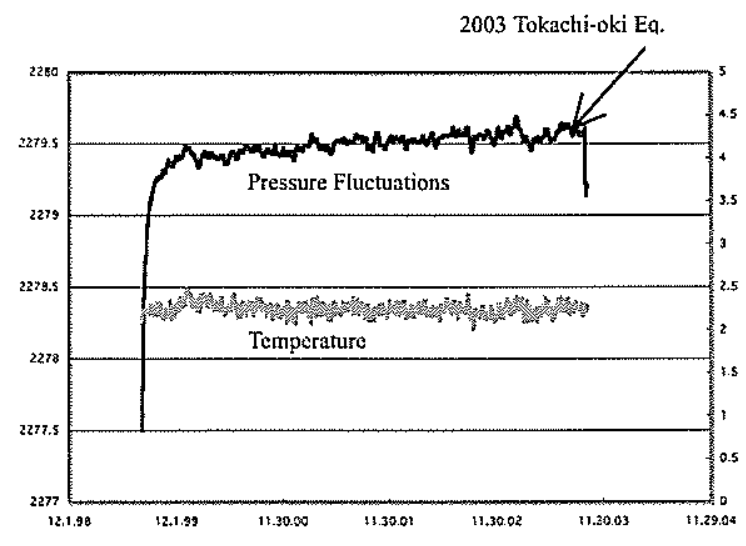

Figure 6 Pressure fluctuations since the installation at PG1 until the 2003 Tokachi-oki earthquake. Scales of the vertical axis for curves are in $\mathrm{m}$ (left) for the pressure and in degrees in Celusius for temperature. Before the earthquake, the pressure change indicates that there could be continuous subsidence of the seafloor.

regarded as a reinforced procedure in stress redistribution along the fault plane. If the steady-state slippage is kept on a surface at the other areas than the asperity of the mainshock, the existence of low frictional surfaces or continuous pressurization in the subsurface could be considered. Detailed discussions on the localization and thickening of aftershock zones should be done and might require much data including land GPS observations as Tsuji et al. (1995) [13] showed for the 1994 Hokkaido Toho-oki earthquake.

As demonstrated in the above section on the tsunami generation process, we have recorded acoustic standing waves caused by the seafloor uplift for the first time. Also it was shown that approximate 
pressure fluctuations can be expressed by seafloor uplift velocity and displacement under the assumption of constant velocity uplift. Both the tsunami and acoustic pressure fluctuations are caused by the same uplift, one constrains the other in the real estimation of the seafloor movement. If we take the current approximate amplitude estimation, we would be able to obtain ca. 3 seconds for effective duration of the seafloor uplift. We think that the change in water depth would be more abrupt than having been considered. The amplitude of the tsunami at each pressure gauge location is the same as the uplift amount of the seafloor and the amplitude of the acoustic pressure fluctuations is proportional to uplift velocity. We think that the pressures observed on the seafloor would be explained by superposed fluctuations such as tsunami and acoustic waves. Note that the pressure fluctuations due to incident seismic waves are within a few meters in equivalent water depths and the most dominant wave in the recorded pressure signals would be of the acoustic wave.

\section{Summary}

At the time of the 2003 Tokachi-oki earthquake, a megathrust earthquake at the Kuril subduction zone, a cabled observatory recorded invaluable data on both crustal uplift of the seafloor caused by the earthquake. The crustal uplift due to the main shock was estimated as 0.37 and $0.12 \mathrm{~m}$ at locations of the two tsunami gauges located about 31.4 and $81.7 \mathrm{~km}$ away from the epicenter of the main shock. The eastimated rate of the continuous crustal uplifts are about $0.004 \mathrm{~mm} /$ day over two months at the all pressure gauge locations after the main shock. These phenomena must be discussed in detail with the results from other means.

After the main shock, a continuous uplift of the seafloor is observed at the all three pressure gauge locations with an exponential decay in the rate of uplifts. Although the coseismic uplifts show a strong correlation with seismic asperity estimated by various authors, the postseismic uplifts are relatively spaceindependent. Since the distribution of the coseismic uplift values is different from that of the postseismic, we preclude that mechanisms of these seafloor uplifts could be caused by two different causes. Since the postseismic continuous uplifts are observed at all the pressure gauge locations, we think that one of the possible cause of the post-seismic uplift would be of a slip of the plate boundary supplementary to coseismic one. Through the analysis of the data, we now think that there might be at least two directions in observation efforts in future seismogenic studies. One is to deploy long-term observatories to cover as long time as possible compared to the recurrence cycle of plate boundary megathrust earthquakes, and the other to access as close as possible to real seismogenic zone to improve the signal-to-noise ratio in observation properties.

Pressure fluctuations we observed on the seafloor at the time of the earthquake were analyzed for possible cause of high amplitude signals whose magnitude is about several tens of the real seafloor uplift. We think the most predominant signals in the pressure would be caused by acoustic waves caused by the uplift. The order estimate of their amplitude led us to a new insight that the abrupt change in water depth has taken place in a time duration of several seconds. Since both tsunami and acoustic waves are caused by the same phenomena, it would be important to relate them to each other to obtain real seafloor uplift in a time series.

\section{REFERENCES}

[1] T. Watanabe, H. Matsumoto, H. Sugioka, H. Mikada, K. Suyehiro, and R. Otsuka, Offshore Monitoring System Records Earthquake in Japan, EOS Trans., 85 (2), 14, 2004.

[2] K. Kusunoki and G. Kimura, Collision and extrusion at the Kuril-Japan arc junction, Tectonics, 17 (6), 843-858, 1998.

[3] C. DeMets, R. Godon, F. Argus and S. Stein, Effect of recent revisions to the geomagnetic reversal time scale on estimates of current plate motions, Geophys. Res. Lett., 21, 2191-2194, 1994.
[4] Y. Yamanaka and M. Kikuchi, Source processes of the recurrent Tokachi-oki earthquake on September 26,2003, inferred from teleseismic body waves, Earth Planet. Sci., 55, e21- e24, 2003.

[5] S. Miyazaki, P. Segall, J. Fukuda, and T. Kato, Space time distribution of afterslip following the 2003 Tokachi-oki earthquake: Implications for variations in fault zone frictional properties, Geophys. Res. Lett., 31, L06623, doi:10.1029/2003GL019410, 2004. [6] H. Takahashi, V. Bahtiarov, V. Levin, E. Gordeev, F. Korchagin, M. Gerasimenko, M. Kasahara, F. Kimata, S. Miura, K. Heki, T. Seno, T. Kato, N. Vasilenko and A. Ivashchenko, Velocity field of around the Sea of Okhotsk and Sea of Japan regions determined from a new continuous GPS network data, Geophys. Res. Lett., 26 (16), $2533-2536,1999$.

[7] H. Takahashi and M. Kasahara, Seismic activity off Tokachi region, Hokkaido, Japan, Zisin (J. Seism. Soc. Japan), 2004 (in Japanese with English abstract), in press.

[8] M. Takeo, S. Ide and Y. Yoshida, Y., The 1993 Kushiro-Oki, Japan, earthquake: A high stress-drop event in a subducting slab, Geophys. Res. Lett., 20 (23), $2607-2610,1993$.

[9] H. Takahashi and K. Hirata, The 2000 Nemuro-Hanto-Oki earthquake, off eastern Hokkaido, Japan, and the high intraslab seismic activity in the southwestem Kuril Trench, J. Geophys. Res., 108 (B4 ), 2178, doi: 10.1029/2002JB001813, 2003.

[10] K. Hirata, M. Aoyagi, H. Mikada, K. Kawaguchi, Y. Kaiho, R. Iwase, S. Morita, I. Fujisawa, H. Sugioka, K. Mitsuzawa, K. Suyehiro, H. Kinoshita, N. Fujiwara, Real-time geophysical measurements on the deep seafloor using submarine cable in the southeastem Kurile subduction Zone, IEEEJ. Ocean. Eng., 27, 170 $181,2002$.

[11] K. Matsumoto, T. Takanezawa and M. Ooe, Ocean Tide Models Developed by Assimilating TOPEX/POSEIDON Altimeter Data into Hydrodynamical Model: A Global Model and a Regional Model Around Japan, J. Oceanography, 56, 567-581, 2000.

[12] K. Kajiura, Tsunami source, energy and the directivity of wave radiation, Bull. Earthq. Res. lnst., 48, 835-869, 1970.

[13] H.Tsuji, Y. Hatanaka, T. Sagiya and M. Hashimoto, Coseismic crustal deformation from the 1994 Hokkaido-Toho-Oki earthquake monitored by a nationwide continuous GPS array in Japan, Geophys. Res. Lett., 22(13), $1669-1672,1995$.

\author{
Hitoshi Mikada, D. Sc. \\ Dept. Civil and Earth Resources Engineering \\ Graduate School of Engineering \\ Kyoto University \\ Yoshida-Hommachi, Sakyo-ku, Kyoto, 606-8501 \\ JAPAN \\ email:mikada@gakushikai.jp
}

